\title{
Preparation of Multilayered Materials in Cross-Section for In Situ TEM Tensile Deformation Studies
}

\author{
M. A. Wall
}

T. W. Barbee, Jr.

This paper was prepared for submittal to the Materials Research Society Spring Meeting San Francisco, CA

March 31-April 4, 1997

May 13, 1997

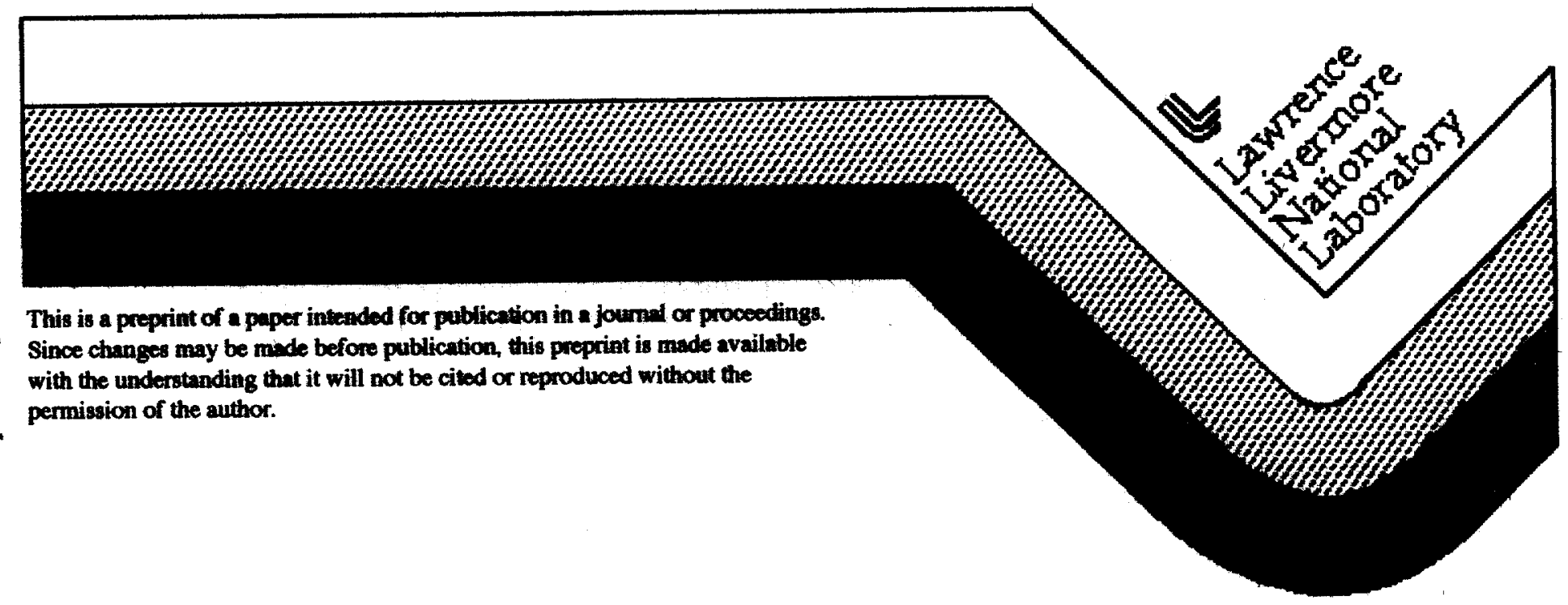




\section{DISCLAIMER}

This document was prepared as an account of work sponsored by an agency of the United States Government. Neither the United States Government nor the University of California nor any of their employees, makes any warranty, express or implied, or assumes any legal liability or responsibility for the accuracy, completeness, or usefulness of any information, apparatus, product, or process disclosed, or represents that its use would not infringe privately owned rights. Reference herein to any specific commercial product, process, or service by trade name, trademark, manufacturer, or otherwise, does not necessarily constitute or imply its endorsement, recommendation, or favoring by the United States Govermment or the University of California. The views and opinions of authors expressed herein do not necessarily state or reflect those of the United States Government or the University of California, and shall not be used for advertising or product endorsement purposes. 


\title{
PREPARATION OF MULTILAYERED MATERIALS IN CROSS-SECTION FOR IN-SITU TEM TENSILE DEFORMATION STUDIES
}

\author{
M. A. WALL, T. W. BARBEE, Jr.
}

L-350, Chemistry \& Materials Science Department, Lawrence Livermore National Laboratory, 7000 East Ave., Livermore, CA USA 94550

\begin{abstract}
. . .
The success of in-situ : transmission electron microscopy experimentation is often dictated by proper specimen preparation. We report here a novel technique permitting the production of crosssectioned tensile specimens of multilayered films for in-situ deformation studies. Of primary importance in the development of this technique is the production of an electron transparent microgauge section using focused ion beam technology. This micro-gauge section predetermines the position at which plastic deformation is initiated; crack nucleation, growth and failure are then subsequently observed.
\end{abstract}

\section{INTRODUCTION}

Transmission electron microscopy (TEM) has provided a vital link between a materials microstructure and its physical properties. However, one limitation of TEM as a characterization technique is the fact that most observations are only static or "post mortem", allowing only indirect conclusion about the mechanisms of microstructural evolution. In-situ TEM techniques allow for the possibility of overcoming this limitation through direct observation of materials under dynamic conditions; a review of a number of in situ TEM experiments can be found in [1].

Multilayers are alternately layered, fine structured materials. Since the structural scale of these nanostructured materials is comparable to the thickness of the typical TEM specimen, the ability to compare the dynamic reaction in a thin foil to bulk behavior becomes more realistic. The static characterization of multilayers and thin films has received considerable attention. [2] and [3]), are recent examples. The majority of in-situ TEM experiments performed on these types of materials has been related to the annealing in order to observe stability and phase transformations; [4] reviews a number of successful in-situ TEM heating experiments. To date there has been little or no work reported on in-situ TEM observations of mechanical deformation in thin films or multilayered materials. The first observations of this nature were reported by [5].

TEM characterization of multilayered materials is typically performed in both plan view and in cross-section. Plan view specimen preparation is straight forward with cross-sectional preparation technique being somewhat more tedious. A number of variations and modifications of crosssectional techniques have been reported [6], [7] and [8]. As with conventional TEM, the success of in-situ TEM experiments may hinge upon proper specimen preparation. We will describe in detail a technique for preparing cross-sectioned, thick, multilayered films that have a micro-gauge section to be used in in-situ tensile deformation experiments. This technique is a modification of a specimen preparation and sample design procedure described by [9]. Observations from initial insitu experiments are also included.

\section{MATERIALS AND METHODS}

\section{SAMPLE}

The sample from which our cross-sectional tensile specimens are made is a copper $(80.0$ $\mathrm{nm}) /$ zirconium $(9.0 \mathrm{~nm})$ multilayer foil containing 1350 periods for a total thickness of $\approx 120$ microns. The $\mathrm{Cu} / \mathrm{Zr}$ multilayer was synthesized by planar magnetron sputtering onto a glass substrate. General characterization of the as-deposited microstructure has been reported by [10]. 
The basic procedure for preparing in-situ tensile specimens includes the following steps: electroplating, slicing and lapping, dimpling, low angle ion milling and focused ion beam milling. The in-situ tensile specimens were deformed in a tensile stage while viewing in the Kratos 1.5 MeV HVEM located at the National Center for Electron Microscopy, Lawrence Berkeley National Laboratory.

\section{ELECTROPLATING}

To prepare the multilayer sample for electroplating the thick multilayer foil should be released from its substrate. The following steps should then be followed. Extract a strip measuring $4 \mathrm{~mm}$ wide by $10 \mathrm{~mm}$ long from the free-standing multilayer foil. Attach one end of the strip to a small brass tab using an electrically conductive epoxy, see figure 1. The brass tab/specimen (cathode) strip is then attached to an electrical feed through and placed into the copper sulfate bath [11]. The plating bath geometry, chemistry and plating parameters are shown in figure 2 . It is important to insure that the flat surfaces of the multilayer foil strip are parallel and equal-distant $(\approx 50 \mathrm{~mm})$ from the sacrificial copper plates (anode). Plate continuously for approximately for $200 \mathrm{hrs}$. until a dense, rectangular shape, is deposited with the minimum dimensions for extracting tensile bars; 4 $\mathrm{mm}$ wide by $10 \mathrm{~mm}$ long by $10 \mathrm{~mm}$ thick, see figure 3 .

\section{SLICING AND LAPPING}

When the electroplating is completed, the electroplated deposit is sliced or machined into a rectangular shaped block having the dimensions of $4 \mathrm{~mm}$ wide by $10 \mathrm{~mm}$ long by $10 \mathrm{~mm}$ thick with the multilayer foil located in the center of the electroplate. The width and length are the lateral dimensions of the tensile bar to be attached to the tensile specimen holder platens. The rectangular block is then sectioned into $400 \mu \mathrm{m}$ thick slices perpendicular to the multilayer foil using a low speed thin diamond saw. The slices are then lapped using a gravity feed lapping device*. Using a succession of finer grit abrasive paper, the slices are lapped equally from both sides to a final thickness of 150 to $175 \mu \mathrm{m}$. 400 grit SiC paper can be used first for the bulk of the lapping with 30 and $12 \mu \mathrm{m} \mathrm{Al}_{2} \mathrm{O}_{3}$ lapping film used to polish the surfaces prior to dimpling.

\section{DIMPLING}

Dimpling is the last abrasive pre-thinning step, and it is also the first step to pre-locate the electron transparent region. Dimpling is performed from one side of the specimen only, directly on top of the multilayer, using a Precision Dimpler**. The dimpling parameters are: $15 \mathrm{~mm}$ diameter phosphor-bronze tool, 25 gram load and a tool speed of $60 \mathrm{rpm}$. Using $10 \mu \mathrm{m} \mathrm{SiC}$ in a kerosene slurry dimple to $20 \%$ of the specimen thickness. Another 10 to $15 \mu \mathrm{m}$ are then removed with a $2-4$ $\mu \mathrm{m}$ cubic born nitride (CBN) in a kerosene slumy. The coarse dimpling surface damage is removed by a final polishing with $2 \mu \mathrm{m}$ CBN on a felt wheel for several minutes. Staring with an initial specimen thickness of $150-175 \mu \mathrm{m}$, the final specimen thickness at the bottom of the dimple is $\approx 12-15 \mu \mathrm{m}$. Figure 4 shows a sliced, lapped and dimpled sample ready for ion milling.

\section{MILLING}

The final two steps are low angle ion milling and focused ion beam milling. Ion milling is performed using a Dual Ion Mill* using the following parameters: simultaneous ion milling of both sides at an angle of 6 degrees, $6-7 \mathrm{keV}, 1 \mathrm{~mA}$ gun current, 40 degrees sector speed control of the specimen rotation and a maximum sensitivity on the termination system. To facilitate low angle ion milling of a large specimen from both sides simultaneously, a minor modification to the specimen clamping plates is necessary. First; the top clamping plate is not used to clamp the specimen in place; Duco ${ }^{\mathrm{TM}}$ cement is used to bond the specimen to the bottom plate (dimple side up). The Duco cement is quite stable under these conditions and dissolves well in acetone. Second, prior to 
cementing the specimen to the support plate, the $2.3 \mathrm{~mm}$ diameter hole in the bottom plate is enlarged to $=6 \mathrm{~mm}$. This moves the inside edge of the support plate back so as to not cast a ion beam milling shadow across the central region of the bottom of the specimen. Ion milling is performed continuously, beyond initial perforation of the specimen, and until a perforation exists at one or both of the multilayer-Cu plating interfaces. Because of the differential ion milling rates of the $\mathrm{Cu}$ plating and the multilayer foil, perforation usually appears in the copper plating near the interface first. Ion milling should continue until a short length $=50-100 \mu \mathrm{m}$ along at least one of the multilayer-Cu plating interfaces is exposed. At this point an effective gauge section exists.

Focused ion beam milling (FIBM) is the final step: FIBM is performed using a PIMS** system. FIBM is isèd to etch a rectangular shaped "notch" into the multilayered foil in a region. located at the center of the gauge length of the specimen created during the ion milling process. The typical notch dimensions used to date measure 5 to $10 \mu \mathrm{m}$ wide by one half to two thirds the multilayer foil thickness deep. The area of the specimen remaining at the bottom of the notch effectively becomes the micro-gauge section (see figure 5, point $P$ ). At this point the specimen is previewed in the TEM to see if there is electron transparent area at the bottom of the notch. If there is little thin region, then the specimen is retumed to the low angle ion milling procedure for a short time until new thin region is created. Prior to in-situ tests the specimen is ion milled again for 3-4 min. at $2 \mathrm{keV}$ and 10 degrees to reduce ion damage and remove any redeposited material as a result of the low angle or FIBM steps.

\section{RESULTS}

Figure 6 shows an example of a completed cross-sectional $\mathrm{Cu} / \mathrm{Zr}$ tensile specimen ready for insitu deformation testing. The notch can clearly be seen in this very low magnification TEM micrograph. The $\mathrm{Cu}$ plating has been preferentially milled away on one side of the multilayer foil. The effective micro-gauge section is approximately $7 \mu \mathrm{m}$ long by $60 \mu \mathrm{m}$ wide.

Figure 8 shows the results of an in-situ straining experiment. After initial straining and viewing of dislocation motion within the $\mathrm{Cu}$ layers, a number of hard $\mathrm{Zr}$ layers fail thus forming a series of voids. At this point the $\mathrm{Cu}$ layers have elongated and begin to neck down to form the initial crack in the multilayer. The crack has formed from the notch base in the electron transparent region, as expected. Further, tensile deformation results in the growth of the voids and ductile failure of the $\mathrm{Cu}$ ligaments. See [5] for a more detailed discussion of these in-situ results.

\section{DISCUSSION}

There can often be a number of different techniques which can be used to produce a specific TEM specimen. These different techniques often have their own unique advantages and disadvantages, such as: the amount of time to make the specimen, availability of specific preparation equipment, individual experience, minimization of preparation induced artifacts, and the amount and location of electron transparent regions. The following is a general discussion of the procedure detailed here.

Electroplating a small specimen to bulk dimensions can be a slow process. In our example, copper was chosen as a plating material for its simple chemistry and plating parameters, the ability to have mechanical strength to "grip" to multilayer foil, and a best match to the thinning properties of the $\mathrm{Cu}$ based multilayer foil. The time for electroplating can be reduced by increasing the bath temperature and increasing agitation.

Using commonly available lapping devices and abrasive media for lapping ensures the production of specimens with flat, parallel surfaces with minimal mechanical damage. Specimens with flat, parallel sides, will facilitate accurate specimen thickness measurement prior to dimpling and ensure proper fixturing in the tensile specimen holder. The thickness to which specimens are to be lapped should be predetermined based on the anticipated minimum ion milling to be used and the mechanical integrity of a thin specimen, [9].

Dimpling can be considered as being a "selected area" metallographic procedure and is a critical step. The dimple center is located directly on top of the middle of the $125 \mu \mathrm{m}$ wide multilayer foil. Copper can be a difficult material to dimple because of its tendency to smear rather than fracture as hard materials do, i.e. Si. Diamond abrasives can often prove useless with materials like copper. 
$\mathrm{SiC}$ and $\mathrm{CBN}$ are far superior for dimpling ductile metals. Dimpling to $<15 \mu$ is possible, but the risk of mechanical damage to the ductile multilayer foil increases and fracturing the electroplating bond becomes highly probable. Dimpling to a thinner specimen thickness does reduce ion milling time, and thus has a positive effect on the differential ion milling. In our example though, there is a small ion milling rate difference between the multilayer foil and plating material. The use of low angle ion milling in combination with sector speed rotation control can further reduce the effects of differential ion milling.

Ion milling at low angles is possible with these larger than normal ( $>3 \mathrm{~mm}$ diameter) specimens with a few simple modifications to the specimen mounts. By removing the top clamping plate, enlarging the bottom suppoit plate hole, and using Duco cement to fix the specimen in place, one can simultaneously ion mill both sides of the specimen at low angles ( $<10$ degrees) on a standard ion mill. Also, low angle ion milling typically increases the amount of uniformly thin electron vagtageo ustransparent area in a cross-section sample. This is advantages because the FIBM procedure will unevenly etch away some of this uniform thin area.

Upon perforation from the low angle ion milling procedure a specimen typically will have considerable electron transparent area. For the deformation experiments however, it is not known precisely where the majority of the plastic deformation and eventual failure of the multilayer will take place. In order to isolate the deformation and failure point for viewing and recording during HVEM observation at higher magnifications, a notch is milled in the gauge section using focused ion beam milling. From our experience the notch width should be at least one half the thickness of the cross-section of the multilayer foil and $<10 \mu \mathrm{m}$ long. It is reasonable to believe that other notch geometry's may work also. Tilting the specimen to greater than $45^{\circ}$ from normal incidence during the FIBM procedure helps to ensure the presence of electron transparent area at the notch base.

\section{CONCLUSIONS}

A procedure for preparing thick multilayered foils in cross-section for in-situ HVEM tensile deformation experiments has been detailed. Of primary importance is the production of a microgauge section using FIB technology. The reported results from an in-situ experiment validate the success of this technique. The method is reproducible and applicable to other thin film and multilayered materials. Specimen preparation includes electroplating, slicing, lapping, dimpling, ion milling and focused ion beam milling; each step has been described and discussed. The results of an in-situ tensile test of a $\mathrm{Cu} / \mathrm{Zr}$ multilayer has also been presented.

\section{ACKNOWLEDGMENTS}

The authors wish to thank Richard Gross of Lawrence Livermore National Laboratory for his technical support. This work was performed under the auspices of the US Department of Energy by the Lawrence Livermore National Laboratory under contract W-7405-Eng-48.

*Product of VCR Group Inc., Suite 32, 250 Grand Ave., South San Francisco, CA 94080.

**Product of Gatan, Inc., 6678 Owens Drive, Pleasanton, CA, USA.

\section{References}

1. Butler ,E. P., Proceedings of the 38th Electron Microscopy Society of America, Claton Publishing Div., Baton Rouge, Louisiana, 12, (1980).

2. Matthews, J. W. and Blakeslee, A. E., J. of Crystal Growth, 27, 118, (1974).

3. Baxter, C. S. and Stobbs, W. M., Ultramicroscopy, 16, 213, (1985).

4. Sinclair, R., Proceedings of the 47th Annual Meeting of the Electron Microscopy Society of America, San Francišco Press, San Francisco, California, 638 (1989). 
5. Wall, M. A., Barbee Jr., T. W. and Weihs, T. P. (1995), In-Situ high voltage electron microscopy technique for the study of deformation and fracture: Multilayered materials, to be presented at the MRS Spring 1995 meeting, Symposia G.

6. Alani, R. and Swann, P. R, Proceedings of the 49th Electron Microscopy Soc. of America. San Francisco Press, Inc., San Francisco, California, 1104, (1991).

7. Bravman; J. C. and Sinclair; J: Electron Microscopy Technique 1,53. (1984).

8. Newcomb, S. B., Boothroyd, C.. B.and Stobbs, -W..M., J. Microscopy, 140, 195, (1985). :

9. Wall, M. A., Microscopy Research and Technique, 27, 262, (1994).

10. Weihs, T. P., Wall, M. A., and Barbee Jr., T. W. Proc., MRS publications, 308, 753, (1994).

11. Blum, W. and Hogaboom, G. B., Principles of electroplating and electroforming, McGraw-Hill, New York, 290, (1949).

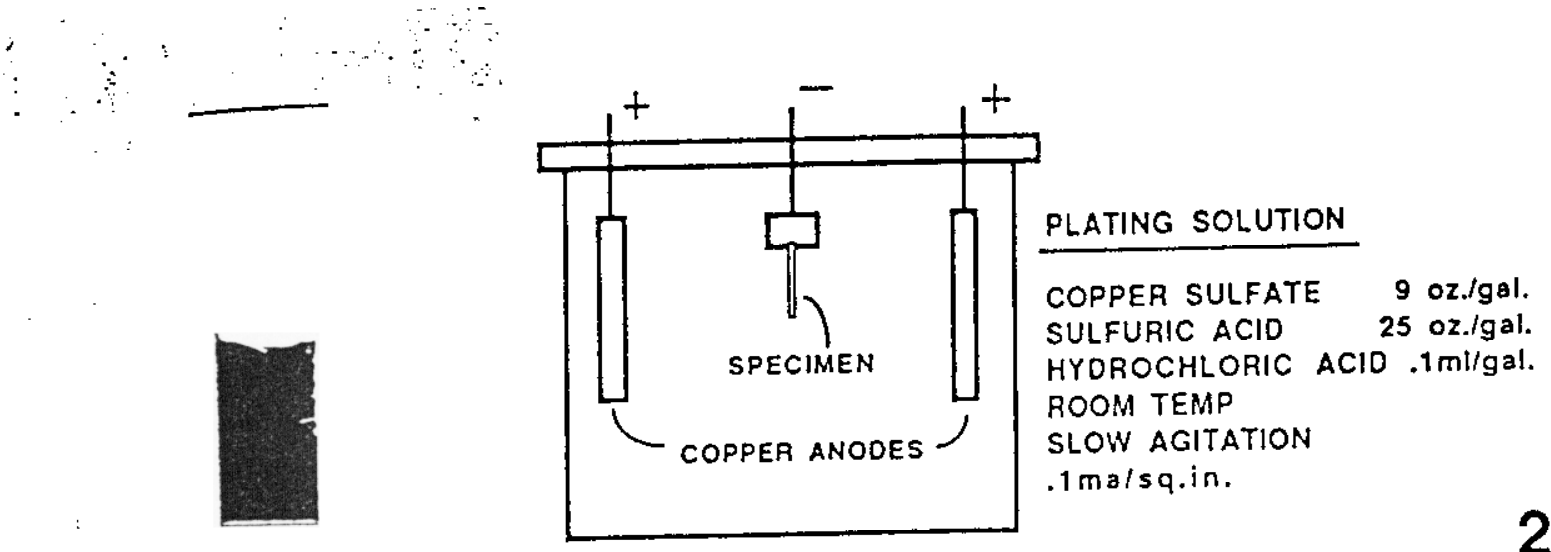

\section{$5 \mathrm{~mm}$}

Figure 1. Optical micrograph of an extracted multilayer foil strip attached to a brass tab with

Figure 2. Drawing of plating bath geometry with a listing of the plating bath chemistry and plating parameters.

\section{3}

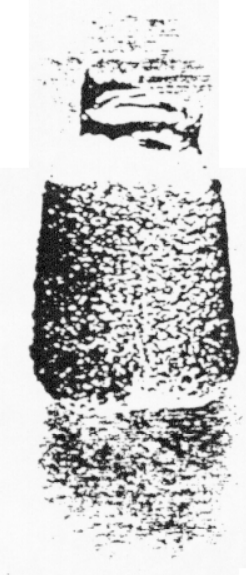

$5 \mathrm{~mm}$

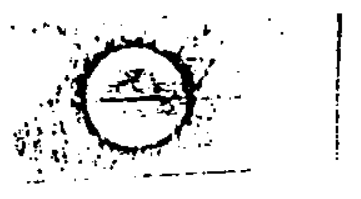

Figure 3. Optical micrograph of a copper plated multilayer foil.

Figure 4. Optical micrograph of a specimen which has been sliced, lapped and dimpled prior to ion milling. 

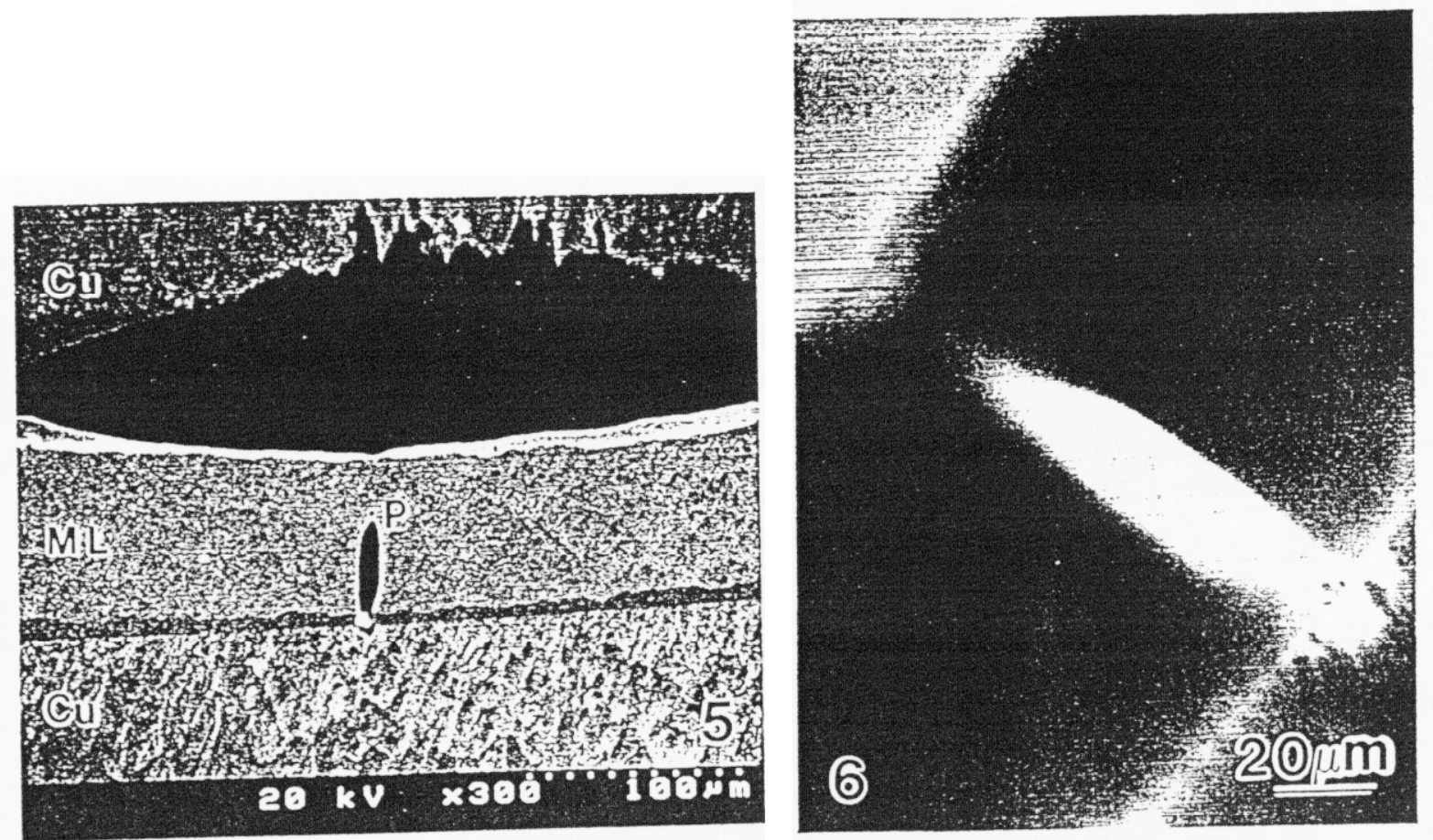

Figure 5. Scanning electron micrograph of a specimen which has been ion milled beyond initial perforation. A short length of the multilayer/copper plating interface has been exposed. A notch measuring $7 \times 60 \mu \mathrm{m}$ has been created by FIBM. Point (P) locates the electron transparent region in the micro gauge section.

Figure 6. Low magnification TEM micrograph of a FIBM notched multilayer foil in crosssection prior to in-situ tensile deformation.
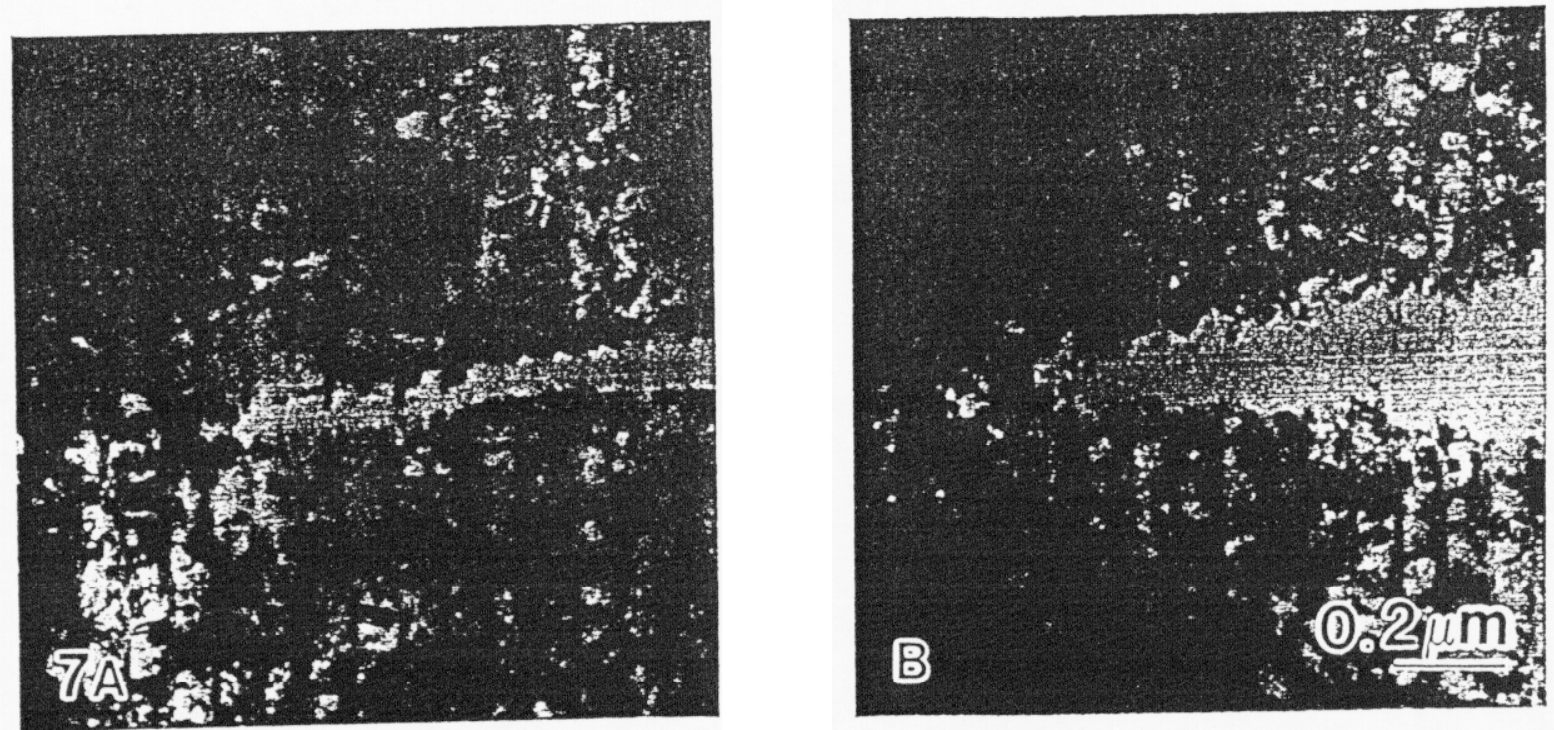

Figure 7. TEM micrographs of an in-situ tensile deformation experiment. A) after initial straining, a crack has formed at the base of the notch base. The thin $\mathrm{Zr}$ layers have failed forming voids and the $\mathrm{Cu}$ layers have elongated forming a series of ligaments. B) Continued straining, voids grow and the $\mathrm{Cu}$ ligaments elongate and neck down to failure. Crack propagation continues with $\mathrm{Zr}$ layer void formation in front of the crack tip. 


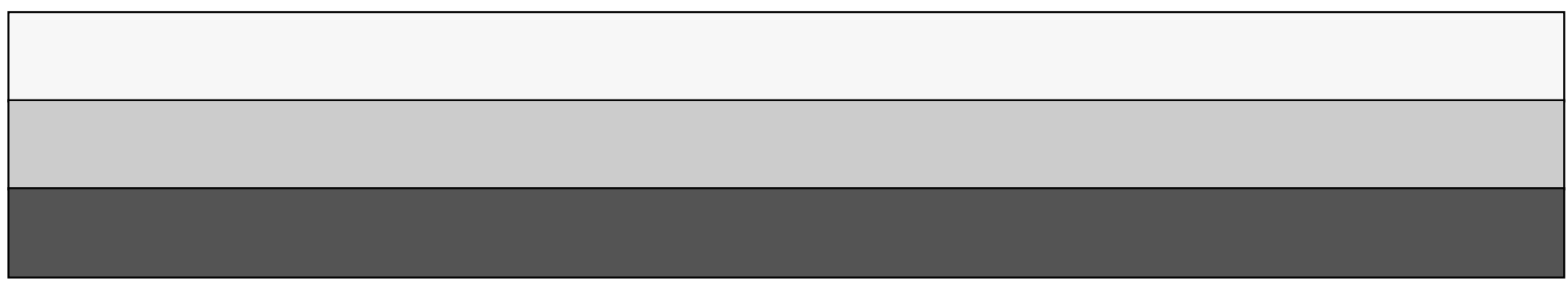

